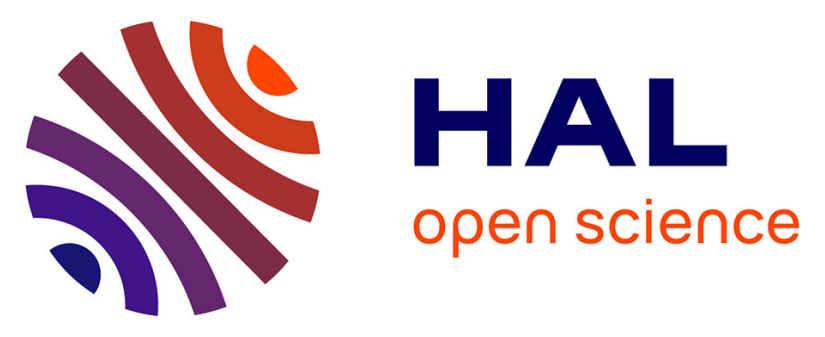

\title{
A soft-chemistry assisted strong metal-support interaction on a designed plasmonic core-shell photocatalyst for enhanced photocatalytic hydrogen production
}

Getaneh Diress Gesesse, Cong Wang, Bor Kae Chang, Shih-Hsuan Tai, Patricia Beaunier, Robert Wojcieszak, Hynd Remita, Christophe Colbeau-Justin, Mohamed Nawfal Ghazzal

\section{- To cite this version:}

Getaneh Diress Gesesse, Cong Wang, Bor Kae Chang, Shih-Hsuan Tai, Patricia Beaunier, et al.. A soft-chemistry assisted strong metal-support interaction on a designed plasmonic core-shell photocatalyst for enhanced photocatalytic hydrogen production. Nanoscale, 2020, 10.1039/C9NR09891G . hal-02521511

\section{HAL Id: hal-02521511 \\ https://hal.science/hal-02521511}

Submitted on 23 Nov 2021

HAL is a multi-disciplinary open access archive for the deposit and dissemination of scientific research documents, whether they are published or not. The documents may come from teaching and research institutions in France or abroad, or from public or private research centers.
L'archive ouverte pluridisciplinaire HAL, est destinée au dépôt et à la diffusion de documents scientifiques de niveau recherche, publiés ou non, émanant des établissements d'enseignement et de recherche français ou étrangers, des laboratoires publics ou privés. 


\title{
A soft-chemistry assisted strong metal-support interaction on a designed plasmonic core-shell photocatalyst for enhanced photocatalytic hydrogen production
}

\section{Getaneh Diress Gesesse, ${ }^{a}$ Cong Wang, ${ }^{a}$ Bor Kae Chang, ${ }^{\text {b }}$ Shih-Hsuan Tai, ${ }^{\text {b }}$ Patricia Beaunier, ${ }^{\mathrm{c}}$ Robert Wojcieszak, ${ }^{d}$ Hynd Remita, ${ }^{\mathrm{a}}{ }^{\mathrm{C}}$ Christophe Colbeau-Justin ${ }^{\mathrm{a}}$ and Mo- hamed Nawfal Ghazzal*a}

\author{
${ }^{a}$ Laboratoire de Chimie Physique, UMR 8000 CNRS, Université Paris-Sud, Université Paris-Saclay 91405 Orsay, France \\ E-mail: mohamed-nawfal.ghazzal@u-psud.fr \\ ${ }^{b}$ Department of Chemical and Materials Engineering National Central University No. 300, Jhongda Rd., Jhongli District, \\ Taoyuan City 32001, Taiwan \\ ${ }^{c}$ Sorbonne Université, CNRS, Laboratoire de Réactivité de Surface, F-75005 Paris Cedex 05, France. \\ ${ }^{d}$ Univ. Lille, CNRS, Centrale Lille, ENSCL, Univ. Artois, UMR 8181 - UCCS - Unité de Catalyse et Chimie du Solide, F- \\ 59000 Lille, France \\ Supporting Information Placeholder
}

\begin{abstract}
Engineering photocatalysts based on gold nanoparticles (AuNPs) has attracted great attention for the solar-to-energy conversion due to their multiple and unique properties. However, there are ambiguities regarding plasmonic photocatalysts configuration and the mechanism behind the photocatalytic production of $\mathrm{H}_{2}$ in core-shell system. In this study, we investigated the rate of $\mathrm{H}_{2}$ production over designed mutually reverse configurations, $\mathrm{SiO}_{2} @ \mathrm{Au} @ \mathrm{TiO}_{2}$ and $\mathrm{SiO}_{2} @ \mathrm{TiO}_{2} @ \mathrm{Au}$, as well as the effect of the AuNPs loading. We found an improvement of the photocatalytic hydrogen efficiency, boosted by the $\mathrm{TiO}_{2}$ thin overlayer covering finely dispersed AuNPs, forming a strong metal-support interaction (SMSI) compared to conventional system. Furthermore, the pathway of the charge carriers' dynamics occurred regarding the system configuration are found to be different. The photogenerated electrons are collected by AuNPs in classical a $\mathrm{SiO}_{2} @ \mathrm{TiO}_{2} @ \mathrm{Au}$ system, while, unconventionally, they are injected back in the titania surface for an $\mathrm{SMSI} \mathrm{SiO}_{2} @ \mathrm{Au} @ \mathrm{TiO}_{2}$ system. Additionally, the adsorption energy of methanol, theoretically estimated using density functional theory (DFT) methodology, is lower for soft-chemistry SMSI photocatalyst compared to conventional systems, accelerating the kinetics of photocatalytic hydrogen production. Soft chemistry of SMSI opens up a designing concept for highly efficient photocatalytic materials, where the photons-to-energy conversion remains a major challenge.
\end{abstract}

KEYWORDS: Core-shell nanostructures, Photocatalysis, Hydrogen production, Gold nanoparticles, Titanium dioxide, Solar energy, Solar fuels, SMSI.

In the last decade, hydrogen, as a chemical fuel, becomes an alternative solution to fossil sources of energy. Hydrogen is usually produced from a variety of feedstocks, including fossil resources, such as natural gas and coal. A large variety of processes is used for its production; including chemical, biological electrolytic, photolytic and thermo-chemical methods. The photocatalytic production of hydrogen from aqueous alcohol solutions, such as methanol and ethanol, appears as a viable and attractive process based on the conversion of sustainable solar energy to chemical fuel. Since the pioneering work of Kawai et al. ${ }^{1}$ and Courbon et al. ${ }^{2}$, many attempts have been made to increase the photocatalytic efficiency of titanium dioxide for hydrogen production. The most promising work involves plasmonic gold nanoparticles (AuNPs), which act as a cocatalyst, charge carriers separator and nanoantena for visible light harvesting. ${ }^{3-11}$. Therefore, the size, shape and the loading of AuNPs appeared as an important parameter to be considered, since they influence the photocatalytic performances. ${ }^{3,4,12,13}$ Engineering the photocatalysts' configuration also had an impact on the photocatalytic activity. Different designs, such as $\mathrm{SiO}_{2} @ \mathrm{Au} @ \mathrm{TiO}_{2}$ and $\mathrm{Au} @ \mathrm{TiO}_{2}$ core-shell nanoparticles ${ }^{12-17}$ or $\mathrm{Au} / \mathrm{TiO}_{2}$ Janus nanoparticles ${ }^{5,6}$ were proposed as an efficient strategy to reach higher photoefficiency. In all cases, the improvement of the photocatalytic performance was attributed to specific properties. The formation of the Schottky contact in the $\mathrm{Au} / \mathrm{TiO}_{2}$ interface was crucial to guarantee efficient electron transport and charge carriers separation under UV-visible and visible illumination. ${ }^{8,18}$ The photocatalytic properties also showed a correlation with the localized surface plasmon resonance intensity (LSPR), rising from the oscillation of elec-

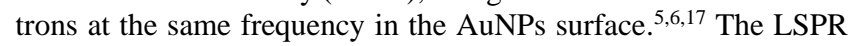
was enhanced by either increasing the size of $\mathrm{Au}$ or $\mathrm{TiO}_{2}$ nanoparticles, leading to the increase in the hydrogen production efficiency. ${ }^{6,19}$ All these systems were studied separately, focusing all the efforts on the improvement of the photocatalytic properties by coupling AuNPs to $\mathrm{TiO}_{2}$. These studies were carried out regardless combining the effect of the charge carriers' dynamics, the localization of AuNPs, the dissociative adsorption of methanol occurring during the photocatalytic production of hydrogen and more importantly the metal-support interaction.

The concept of strong metal-support interaction (SMSI) was introduced in the 1970's by Tauster et al. ${ }^{20}$ The fundamentals of the SMSI method used high-temperature $\mathrm{H}_{2}$ reducing environment, which induces the reduction of the metal oxide and its migration to the top of the metal nanoparticles (encapsulation of the metallic nanoparticles). The method showed some stability issues, since the re-oxidation or the receded of the overlayer during the catalytic reaction, which can induce inactivation of the catalyst and/or reduction of its selectivity. ${ }^{21-23}$ A revisited SMSI methods has emerged claiming higher stability of the overlayer metal oxide and good activity for $\mathrm{CO}_{2}$ reduction. ${ }^{24}$ The method proposed the use of $\mathrm{HCO}_{x}$ adsorbate, which mediated the metal oxide overlayer formation at the surface of $\mathrm{Rh}$ nanoparticles. Most of the time, SMSI was restricted to metals from the group VI, VII and VIII supported on reducible oxides such as $\mathrm{TiO}_{2}, \mathrm{~V}_{2} \mathrm{O}_{3}, \mathrm{Nb}_{2} \mathrm{O}_{5}, \mathrm{Ta}_{2} \mathrm{O}_{5}$, and $\mathrm{CeO}_{2}$. ${ }^{23-}$ ${ }^{27}$ AuNPs were believed to be excluded from forming SMSI with titanium dioxide due to its low work function, surface energy and failure to dissociate molecular hydrogen necessary for the oxide migration to the metal surface..$^{28,29}$ However, recent theoretical and experimental studies demonstrated that gold can dissociate $\mathrm{H}_{2}$ and, hence, promote the reduction of oxide supports ${ }^{30-32}$. Hence, clas- 
sical SMSI ${ }^{29}$ and more recently wet-chemistry SMSI were proposed for deposing substoichiometric $\mathrm{TiO}_{\mathrm{x}}$ at the surface of AuNPs. ${ }^{33}$

In general, the development around the SMSI concept was restricted to heterogeneous catalytic redox reactions. The use of SMSI in photocatalytic reaction has not yet been considered. If this method is accurate for catalytic reaction, in photocatalysis it seems to be inadequate. Indeed, amorphous $\mathrm{TiO}_{2}$ or non-stoichiometric titanium oxide are often obtained under the reductive condition and high temperature treatment, which do not correspond to the preferred anatase photoactive phase. Furthermore, the existence of a consensus regarding the location of AuNPs on the photocatalyst surface meant that the concept was not taken into account. Additionally, the photocatalytic process occurring during the hydrogen production is managed by several parameters such as photogenerated charge carriers dynamics and lifetime, methanol adsorption/desorption, light harvesting, band-gap energy, $\mathrm{TiO}_{2}$ crystallite phase, etc. In this work, the SMSI is considered for the first time for photocatalytic hydrogen production. The main question was "Does the location of the AuNPs has any importance and should they be deposited at the photocatalyst surface for efficient hydrogen production under UV-visible illumination?" To get a reasonable answer, the hydrogen production was studied for two different configurations. In the first one, AuNPs were deposited on the surface of silica-titania core-shell oxides $\left(\mathrm{SiO}_{2} @ \mathrm{TiO}_{2} @ \mathrm{Au}\right)$, and in the second, AuNPs were encapsulated with $\mathrm{TiO}_{2}$ overlayer getting SMSI using our previously reported soft-chemistry method $\left(\mathrm{SiO}_{2} @ \mathrm{Au} @ \mathrm{TiO}_{2}\right)$ (Scheme 1). ${ }^{17}$ The photocatalytic efficiency was assessed following the hydrogen production under UV-visible illumination from aqueous methanolic solution for each system. The photoactivity of the core-shell system was found to be higher when AuNPs were covered by a thin layer of $\mathrm{TiO}_{2}$, following in the same time the evolution of the LSPR intensity. The dynamics of charge carriers studied by time resolved photoconductivity indicates variable pathways suggesting different mechanism of hydrogen production. Finally, the dissociative adsorption energy of methanol at the surface of each system was theoretically simulated by DFT and a mechanism of the hydrogen production was proposed

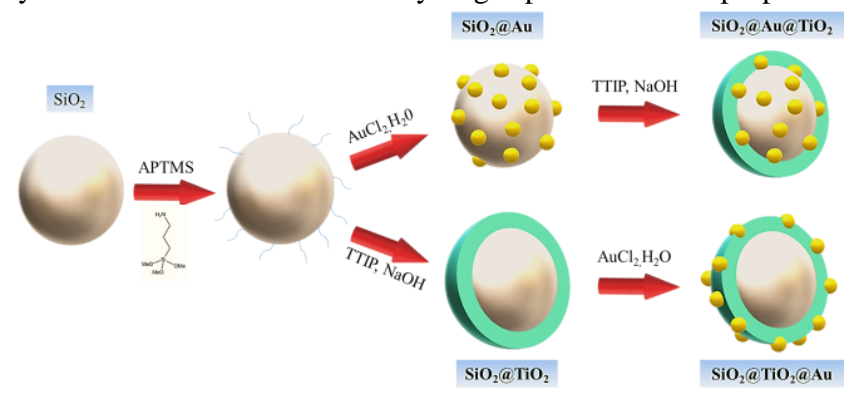

Scheme 1: Scheme of different steps of the synthetic procedure of plasmonic core-shell nanoparticles. AuNPs were loaded on the synthesized $\mathrm{SiO}_{2} @ \mathrm{TiO}_{2}$ core-shell or $\mathrm{SiO}_{2}$ core with a weight ratio $\left(\mathrm{Au} /\left(\mathrm{SiO}_{2}+\mathrm{TiO}_{2}\right)\right.$ est-ce biença?) of $0.25,0.5,1$, and $1.5 \mathrm{wt} \%$.

in order to explain the global kinetics of the hydrogen production rates.

\section{EXPERIMENTAL METHODS}

Materials. All reagents (analytical grade) were used without further purification. Titanium isopropoxide (TTIP), 3-aminopropyltrimethoxy silane (APTMS), tetraethyl ortho silicate (TEOS), chloroauric acid trihydrated $\left(\mathrm{HAuCl}_{4} .3 \mathrm{H}_{2} \mathrm{O}\right)$, tetrakis (hydroxylmethyl)phosphonium chloride (THPC), ammonium hydroxide $\left(\mathrm{NH}_{4} \mathrm{OH}\right)$. Furthermore, Mill-Q water and ethanol absolute (99\%, Aldrich) were used as solvents.
Materials Synthesis. The synthesis of core-shell nanoparticles was reported elsewhere ${ }^{17}$ and is only briefly described here. The Stöber method was used to prepare spherical silica nanoparticles. A mixture of $20 \mathrm{~mL}$ of Mill-Q water and $15 \mathrm{~mL}$ of absolute ethanol was stirred for 10 minutes at room temperature. $5 \mathrm{~mL}$ of $\mathrm{NH}_{4} \mathrm{OH}$ was used to adjust the $\mathrm{pH}$ and the temperature was increased to $40^{\circ} \mathrm{C}$ under magnetic stirring (10 minutes). Then, TEOS $(4.5 \mathrm{~mL})$ was added dropwise to the solution, and aged under magnetic stirring for 1 hour. The white precipitate was obtained and separated by centrifugation. The solid was washed 3 times with Mill-Q water and dried in the oven at $70{ }^{\circ} \mathrm{C}$ overnight.

The functionalization of $\mathrm{SiO}_{2}$ nanoparticles was performed as follows: $\mathrm{SiO}_{2}(250 \mathrm{mg})$ nanoparticles were added to ethanol $(10 \mathrm{~mL})$ while stirring vigorously, followed by sonication for 30 minutes to completely disperse the microspheres. While the colloidal solution stirred, $0.1 \mathrm{~mL}$ of APTMS was added dropwise and kept stirred ( $500 \mathrm{rpm}$ ) for $6 \mathrm{~h}$ at room temperature. The APTMS functionalized silica nanoparticles were collected from the colloidal solution by centrifugation and washed 3 times with absolute ethanol.

Synthesis of $\mathrm{SiO}_{2} @ \mathrm{TiO}_{2}$ core-shell was performed as follow: The APTMS functionalized $\mathrm{SiO}_{2}$ nanoparticles were added to the solution of $20 \mathrm{~mL}$ absolute ethanol and $0.5 \mathrm{~mL}$ of water while stirred vigorously. The nanoparticles were dispersed under sonication for 30 minutes. Concentrated ammonium hydroxide solution $(0.3 \mathrm{~mL}$, $25 \mathrm{wt} \%$ ) was used to adjust the $\mathrm{pH}$, which was recorded (stabilized at 12.4). The solution was stirred for 20 minutes, and a mixture of $50 \mathrm{~mL}$ of absolute ethanol and $1.5 \mathrm{~mL}$ TTIP were added dropwise and left for 2 hours under stirring (1000 rpm) at room temperature. The coated colloidal spheres were separated by centrifugation and washed with absolute ethanol three times. The core-shell nanoparticles were dried in the oven at $80^{\circ} \mathrm{C}$ overnight.

Gold nanoparticles (AuNPs hereafter) were loaded on $\mathrm{SiO}_{2} @ \mathrm{TiO}_{2}$ or embedded between $\mathrm{SiO}_{2}$ and $\mathrm{TiO}_{2}$. Scheme 1 illustrates all the steps of the synthetic procedure of core-shell nanoparticles. AuNPs were loaded on the synthesized $\mathrm{SiO}_{2} @ \mathrm{TiO}_{2}$ core-shell according to Duff and Baiker method, to obtain a weight ratio of $\mathrm{Au} / \mathrm{TiO}_{2} ; 0.25$, $0.5,1$, and $1.5 \mathrm{wt} \%$. First, the synthesized $\mathrm{SiO}_{2} @ \mathrm{TiO}_{2}$ nanospheres were further functionalized with APTMS, as described above. The APTMS functionalized $\mathrm{SiO}_{2} @ \mathrm{TiO}_{2}$ core-shell was separated by centrifugation followed by washing with ethanol 3 times. Another gold containing solution was prepared separately as follows: 1.5 $\mathrm{mL}(0.2 \mathrm{~mol} / \mathrm{L}) \mathrm{NaOH}$ solution was added to $45 \mathrm{~mL}$ of water while stirring vigorously. After 5 minutes of stirring, the solution of THPC ( $1 \mathrm{~mL}, 0.05 \mathrm{~mol} / \mathrm{L}$ ) were added to the prepared solution, followed by addition of adequate amount of $\mathrm{HAuCl}_{4} .3 \mathrm{H}_{2} \mathrm{O}$ to the mixture as gold source to obtain weight ratio of $0.25,0.5,1$, and 1.5 $\mathrm{wt} \%$ respectively. The appearance of red-purple colour indicates the reduction of $\mathrm{Au}$ (III) to $\mathrm{Au}(0)$. The solution was stirred for 30 minutes. Then, APTMS modified $\mathrm{SiO}_{2} @ \mathrm{TiO}_{2}$ core-shell was dispersed in solution containing gold and stirred for 4 hours to control the areal density of Au NPs on the surface of $\mathrm{TiO}_{2}$. The obtained solid material was collected by centrifugation, washed with water 3 times and dried in the oven at $60^{\circ} \mathrm{C}$ for 48 hours. The synthesized product was assigned as $\mathrm{SiO}_{2} @ \mathrm{TiO}_{2} @ \mathrm{Au}$.

A similar procedure was used to synthesize $\mathrm{SMSI} \mathrm{SiO}_{2} @ \mathrm{Au} @ \mathrm{TiO}_{2}$ system, but this time using the silica nanoparticles loaded with adequate amount of AuNPs $(0.25,0.5,1$ and $1.5 \mathrm{wt} \%)$ as a starting material. APTMS functionalized $\mathrm{SiO}_{2}$ core nanoparticles were dispersed in a solution containing the target gold ratio. $\mathrm{SiO}_{2} @ \mathrm{Au}$ nanoparticles with different loading ratios were collected by centrifugation until the supernatant became colorless. The solids were 
washed 3 times with absolute ethanol and dried at $60^{\circ} \mathrm{C}$ for $48 \mathrm{~h}$. APTMS functionalized $\mathrm{SiO}_{2} @$ Au nanoparticles were dispersed in a mixture of $(20 \mathrm{~mL})$ absolute ethanol and $(0.5 \mathrm{~mL})$ of Mill-Q water followed by sonication. Then, $0.3 \mathrm{~mL}$ of concentrated $\mathrm{NaOH}$ was added to adjust the $\mathrm{pH}$ at 12.4 . The solution was stirred for 20 minutes, and a mixture of $(50 \mathrm{~mL})$ absolute ethanol and $(1.5 \mathrm{~mL})$ TTiP was added dropwise. The solution was left under agitation for 2 hours $(1000 \mathrm{rpm})$ at room temperature. The nanoparticles were collected by centrifugation and washed 3 times with absolute ethanol and dried at $80^{\circ} \mathrm{C}$ overnight. All the plasmonic photocatalysts were calcined at $500^{\circ} \mathrm{C}$ for 2 hours under air.

Characterization. The diffusion reflectance spectra (DRS) of the core-shell nanocomposites samples were collected using a Cary5000 spectrophotometer (Agilent) equipped with a Cary 4/5 diffuse reflection sphere. The baseline was recorded using a poly(tetrafluoroethylene) reference. Transmission electron microscopy (TEM) observations and EDS X-ray microanalysis were carried out on a JEOL JEM 2100 Plus transmission electron microscope, operating at $200 \mathrm{kV}$, interfaced to Oxford Instruments AZtec EDS system with an X-Max T large area $\left(80 \mathrm{~mm}^{2}\right)$ SDD detector. The images were collected with a $4008 \times 2672$ pixels CCD camera (Gatan Orius SC1000). TEM images were processed by Image J software. The size estimation and their size distribution were estimated taking into account 150-250 of AuNPs.

ICP-OES (Inductively Coupled Plasma Optical Emission Spectrometry) analysis was performed using Agilent 720-ES ICP-OES equipment combined with Vulcan $42 \mathrm{~S}$ automated digestion system. Vulcan $42 \mathrm{~S}$ is an automated digestion system combining the two essential steps in sample preparation prior to analysis by ICP: sample digestion followed by sample work-up. The digestion procedure was as follows: firstly, $10 \mathrm{mg}$ samples were weighted and $2.4 \mathrm{~mL}$ of aqua regia and $1 \mathrm{~mL}$ of $\mathrm{HF}$ were added to each sample by the robot then heated for 2 hours up to $110^{\circ} \mathrm{C}$ (this step is repeated 3 times), followed by 1 hour heating up to $110^{\circ} \mathrm{C}$. Almost all the digester components are made of Teflon to avoid corrosion with the use of acids. Questrom uses a highly efficient fume removal after neutralizing the acid vapour thereby avoiding cross-contamination. Photocatalytic hydrogen production from an aqueous methanol solution was performed in a closed Pyrex glass reactor under an argon atmosphere and with vigorous stirring. In typical photocatalytic test, the water/methanol 75/25 v/v (final volume was $20 \mathrm{~mL}$ ) solution was stirred under a flow of nitrogen for $30 \mathrm{~min}$ to eliminate dissolved oxygen. Then, $30 \mathrm{mg}$ of the photocatalyst nanocomposite were added to reaction medium (the weight ratio between the solution and the photocatalyst was $\sim 1$ ). The solution is subsequently illuminated using a mercury lamp (150W) light source as an artificial source to simulate the entire solar spectrum. The hydrogen production was simultaneously followed each hour by gas chromatography on a Bruker Scion gas chromatograph, with a thermal conductivity detector (column, molecular sieve $5 \mathrm{~A}, 75 \mathrm{~m} \times 0.53 \mathrm{~mm}$ i.d. oven temperature at $50{ }^{\circ} \mathrm{C}$; flow rate $=22.5 \mathrm{~mL} \mathrm{~min}^{-1}$; detector temperature $=250{ }^{\circ} \mathrm{C}$; carrier gas, nitrogen). For these experiments, $20 \mathrm{mg}$ of each photocatalyst were suspended in $20 \mathrm{~mL}$ of a degassed aqueous solution of methanol $(25 / 75 \mathrm{v} / \mathrm{v})$, and used as a sacrificial agent. Visible light experiment was performed using a cutoff filter (AM-32603-1, LOT-Oriel; $\lambda>450 \mathrm{~nm}$ ).

After UV or visible illumination, the charge carrier lifetimes plasmonic core-shell materials were studied by Time Resolved Microwave Conductivity method (TRMC). For TRMC measurements, the incident microwaves were generated by a Gunn diode of the $\mathrm{K} \alpha$ band at $30 \mathrm{GHz}$. The pulsed light source was an OPO laser (EKSPLA, NT342B) tunable from 225 to $2000 \mathrm{~nm}$. It delivers 8-ns FWMH pulses with a frequency of $10 \mathrm{~Hz}$. The density of light energy received by the sample was at $2.3 \mathrm{~mJ} . \mathrm{cm}^{-2}$ at $350 \mathrm{~nm}$ and 3.7 $\mathrm{mJ} . \mathrm{cm}^{-2}$ for $\lambda=550 \mathrm{~nm}$. To minimize the noise, a TRMC signal is obtained by averaging measurements during 200 laser pulses. The TRMC technique is based on the measurement of the relative change of the microwave power reflected by a sample (semiconductor), during its simultaneous irradiation by a laser pulse. The TRMC technique has been described in more details elsewhere. ${ }^{11,34}$ Computational Methodology. Density functional theory (DFT) calculations at the generalized gradient approximation (GGA) level using CASTEP plane-wave code ${ }^{35}$ were performed with PerdewBurke-Ernzerhof (PBE) density functional ${ }^{36}$ and ultrasoft pseudopotentials. These are prevalent in literature and have been recently used in similar bulk $\mathrm{TiO}_{2}$ calculations. ${ }^{37}$ Plane-wave basis set cutoff energy was set at $620 \mathrm{eV}$, while $\Gamma$-point was sampled in the $\mathrm{k}$ space because of the large supercell models used. Convergence criteria used during full geometry optimization of the $\mathrm{TiO}_{2}$ unit cell include changes in energy of less than $10^{-5} \mathrm{eV} /$ atom, forces on each atom smaller than $0.03 \mathrm{eV} / \AA$, final stress in the unit cell of less than $0.05 \mathrm{GPa}$, and atomic displacements smaller than $0.001 \AA$ A. $3 \times 3 \times 2$ supercell models of anatase $\mathrm{TiO}_{2}$ were constructed based on experimental data, ${ }^{38}$ which was then expanded to $7 \times 1 \times 7$ in order to obtain a big enough structure to create anatase (101) surface with a 15 $\AA$ vacuum layer. The final surface and bulk model contained 96 oxygen atoms and 48 titanium atoms. The silica substrate is not considered in our models, since it does not participate in reactions, thus SMSISiO ${ }_{2} @ \mathrm{TiO}_{2} @ \mathrm{Au}$ and $\mathrm{SiO}_{2} @ \mathrm{Au} @ \mathrm{TiO}_{2}$ were modeled as $\mathrm{TiO}_{2}$ with a small gold cluster on the surface or reversed with the gold cluster embedded below. Au3 gold clusters were added on in our system of anatase (101) surfaces based on previous literature, 38,39 and all atomic positions were fully optimized again without relaxing the cell parameters. DFT-D3 dispersion correction method by Grimm, ${ }^{40}$ which has parameters for gold, was implemented in this study after gold clusters and later methanol molecules were included to correct for London dispersion in this adsorption scenario. Methanol adsorption was considered on both sides of the model described above to simulate the two synthesized materials. During geometry optimization, the bottom layer of the anatase cell was fixed to simulate bulk properties and the top four layers were relaxed. In the case of $\mathrm{Au} @ \mathrm{TiO}_{2}$, both the bottom layer and with the attached gold cluster were fixed during the calculations. Initial distance between methanol and anatase (101) surface or gold cluster is $2.22 \AA$. The adsorption energy of a single methanol molecule is calculated as follows:

$$
\begin{aligned}
& E_{\text {ads }}=E_{\text {methanol+Au@TiO2 }}-\left(E_{\text {Au@TiO2 }}-E_{\text {methanol }}\right) \\
& \text { or } \\
& E_{\text {ads }}=E_{\text {methanol+TiO2@Au }}-\left(E_{\text {TiO2 } @ A u}-E_{\text {methanol }}\right) .
\end{aligned}
$$

\section{Results and Discussion}

The morphology and microstructure of $\mathrm{SiO}_{2} @ \mathrm{Au} @ \mathrm{TiO}_{2}$ and $\mathrm{SiO}_{2} @ \mathrm{TiO}_{2} @ \mathrm{Au}$ nanocomposites were investigated by TEM as depicted in Figure 1. The images exhibit core-shell nanostructures with distinct high-density silica core, much darker than the lowdensity titania shell. The Stöber method enables synthesizing spherical $\mathrm{SiO}_{2}$ nanoparticles with an average diameter of $50-70 \mathrm{~nm}$. 
The hydrolysis followed by the polycondensation of TTIP precursor in alkaline ethanoic mixture $(\mathrm{pH}=12)$, leads to uniform $\mathrm{TiO}_{2}$ shell covering the silica core. The APTMS introduces amine terminal groups at the silica surface providing nucleation sites where the

$\mathrm{TiO}_{2}$ thin shell can homogeneously growth during the sol-gel process. The $\mathrm{TiO}_{2}$ shell thickness, estimated from HR-TEM images, is approximately in the range of 4-10 $\mathrm{nm}$ (Figure 1.a). The high magnification TEM image evidences a crystallized shell with an interplanar spacing of $0.342 \mathrm{~nm}$, consistent with the (101) crystallographic plane of $\mathrm{TiO}_{2}$ anatase (magnification of the dotted square in Figure 1.b). Fast Fourier transform pattern showed a $\mathrm{TiO}_{2}$ anatase thin layer surrounding the (111) face of AuNPs separated with

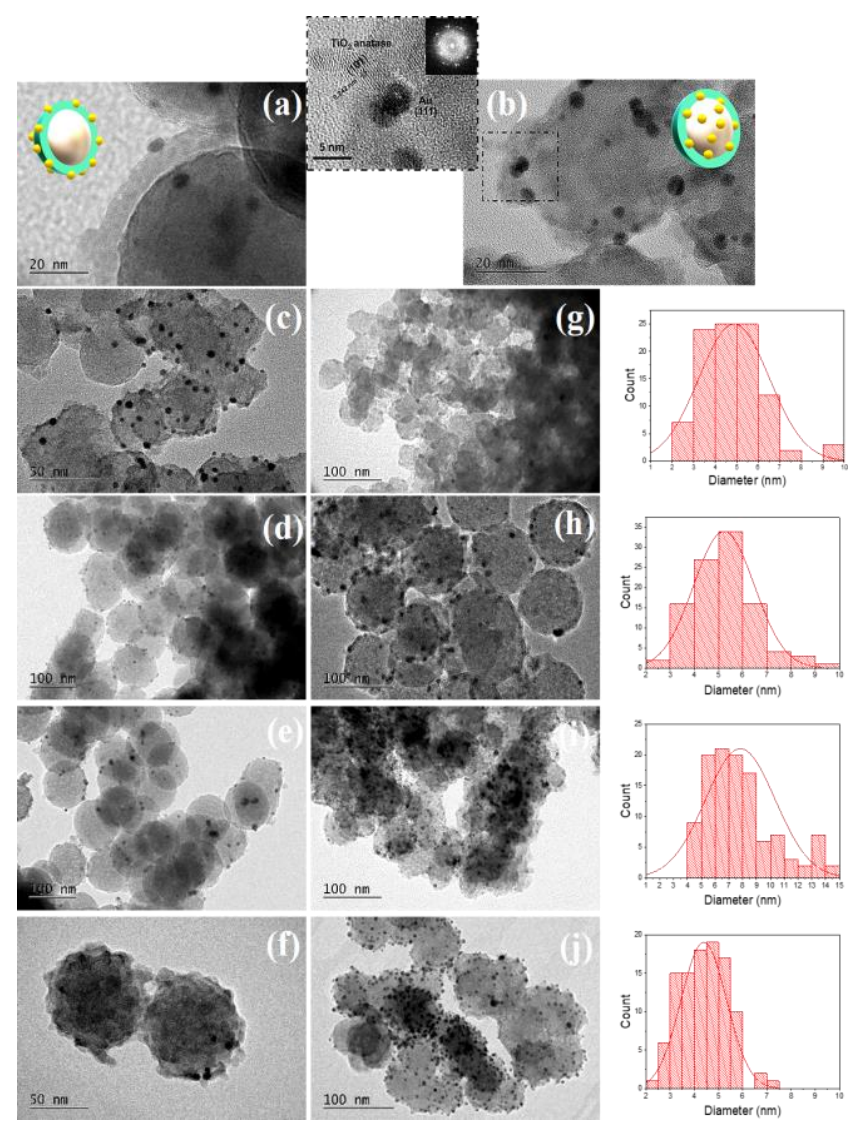

Figure 1 : HR-TEM image of nanocomposites (a) $\mathrm{SiO}_{2} @ \mathrm{TiO}_{2} @ \mathrm{Au}$ with 0.5 wt\% ratio and (b) $\mathrm{SiO}_{2} @ \mathrm{Au} @ \mathrm{TiO}_{2}$ with 1 wt\% ratio, included fast Fourier transform of a rectangular region in HR-TEM. TEM images of (c-f) $\mathrm{SiO}_{2} @ \mathrm{TiO}_{2} @ \mathrm{Au}$ and $(\mathrm{g}-\mathrm{j}) \mathrm{SiO}_{2} @ \mathrm{Au} @ \mathrm{TiO}_{2}$ systems with variable AuNPs loading: (c, g) $0.25 \mathrm{wt} \%$, (d, h) $0.5 \mathrm{wt} \%$, (e, i) $1 \mathrm{wt} \%$, (f, j) $1.5 \mathrm{wt} \%$. The size distribution of Au nanoparticles calculated from TEM images is also presented respectively for each $\mathrm{Au} / \mathrm{TiO}_{2}$ ratio.

interplanar spacing of $0.23 \mathrm{~nm}$ (magnification of the white square in Figure 1.b). The reduction of the $\mathrm{HAuCl}_{4} .3 \mathrm{H}_{2} \mathrm{O}$ precursor occurred efficiently, resulting in the formation of hemispherical AuNPs. The AuNPs weight ratio, as estimated by ICP analysis was $0.13 \%, 0.53 \%, 1.13 \%, 1.56 \%$ is in agreement with the theoretical ratio, except for a lower ratio. The TEM images reveal that the AuNPs exhibit a narrower size distribution with an average size ranging from 4.5 to $7 \mathrm{~nm}$.

More TEM investigations were carried out evidencing the effective SMSI through the formation of thin $\mathrm{TiO}_{2}$ overlayer covered on the AuNPs (Figures $2 \mathrm{a}-\mathrm{d}$ ). $\mathrm{TiO}_{2}$ shell with a thickness of 4-10 nm enables embedding AuNPs inside of an oxide overlayer of 2-3 $\mathrm{nm}$.
The APTMS functionalized AuNPs provides growth sites where the $\mathrm{TiO}_{2}$ thin shell is readily formed.
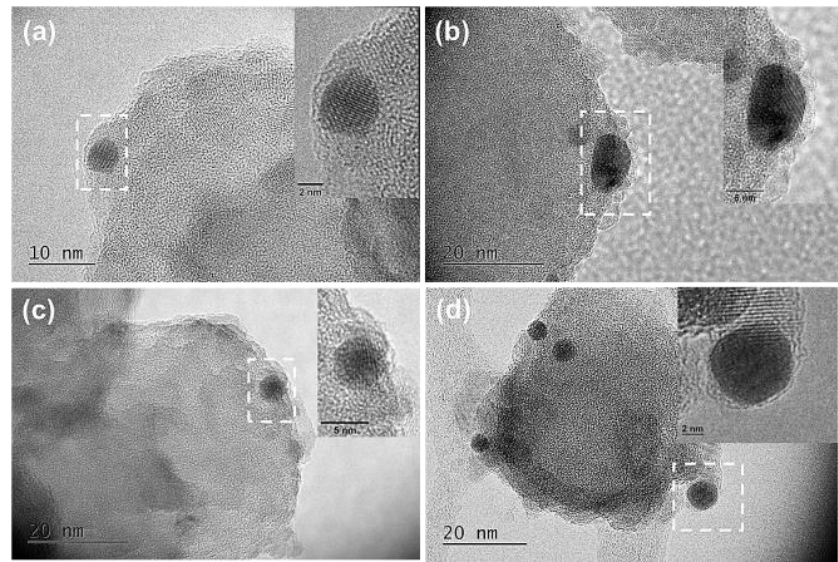

Figure 2: TEM images of $\mathrm{SiO}_{2} @ \mathrm{Au} @ \mathrm{TiO}_{2}$ systems with increasing gold ratio : (a) $0.25 \mathrm{wt} \%$, (b) $0.5 \mathrm{wt} \%$, (c) $1 \mathrm{wt} \%$ and (d) $1.5 \mathrm{wt} \%$.

To go further on the microstructure investigations, HAADF-STEM images and EDS chemical mapping on $\mathrm{SiO}_{2} @ \mathrm{Au} @ \mathrm{TiO}_{2}$ with 0.5 wt $\%$ ratio were performed to obtain more information on the distribution of $\mathrm{Si}, \mathrm{O}, \mathrm{Ti}$ and Au elements (Figure 3). Despite the low thickness of the $\mathrm{TiO}_{2}$ shell, $\mathrm{Ti}$ element uniformly distributed on the surface could be observed. The obtained images confirmed the core-shell structure. The highly dispersive Au element distribution confirms isolated AuNPs on the surface of silica.

The LSPR properties of $\mathrm{SiO}_{2} @ \mathrm{TiO}_{2} @ \mathrm{Au}$ and $\mathrm{SiO}_{2} @ \mathrm{Au} @ \mathrm{TiO}_{2}$ nanocomposites systems with increasing Au loading was studied by steady-state UV-visible diffuse reflectance spectroscopy within the $400-800 \mathrm{~nm}$ wavelength range (Figure $4 \mathrm{a}-\mathrm{b}$ ). Core-shell nanostructures containing AuNPs exhibited LSPR in the visible range. However, the gold-free samples (bare $\mathrm{SiO}_{2} @ \mathrm{TiO}_{2}$ ) showed no absorption in the visible region. $\mathrm{TiO}_{2}$ in anatase form $\left(\mathrm{E}_{\mathrm{g}}=3.2\right.$ eV) absorbs only in the UV region. AuNPs deposited at the $\mathrm{SiO}_{2}$ surface shows a broadband absorption with the maximum at 520 $\mathrm{nm}$ (data not shown). After the $\mathrm{TiO}_{2}$ thin shell was coated, the maximum wavelength of the LSPR band was red-shifted to $541 \mathrm{~nm}$ for the lower $\mathrm{Au} / \mathrm{TiO}_{2}$ ratio. The LSPR wavelength maximum of AuNPs is related to their shape, size and the dielectric constant (refractive index) of the surrounding medium. The size distribution of AuNPs, as estimated from TEM images, indicates very small changes of the AuNPs size distribution regardless of the loading. Therefore, following up on our procedure, the small change of the nanoparticle diameter could not explain the observed red-shift. Indeed, tuning the size of AuNPs needs more sophisticated methods such as the use of stabilizers ${ }^{41}$ or complex growth method. ${ }^{42}$ The AuNPs spatial separation is too large avoiding any strong near-field 

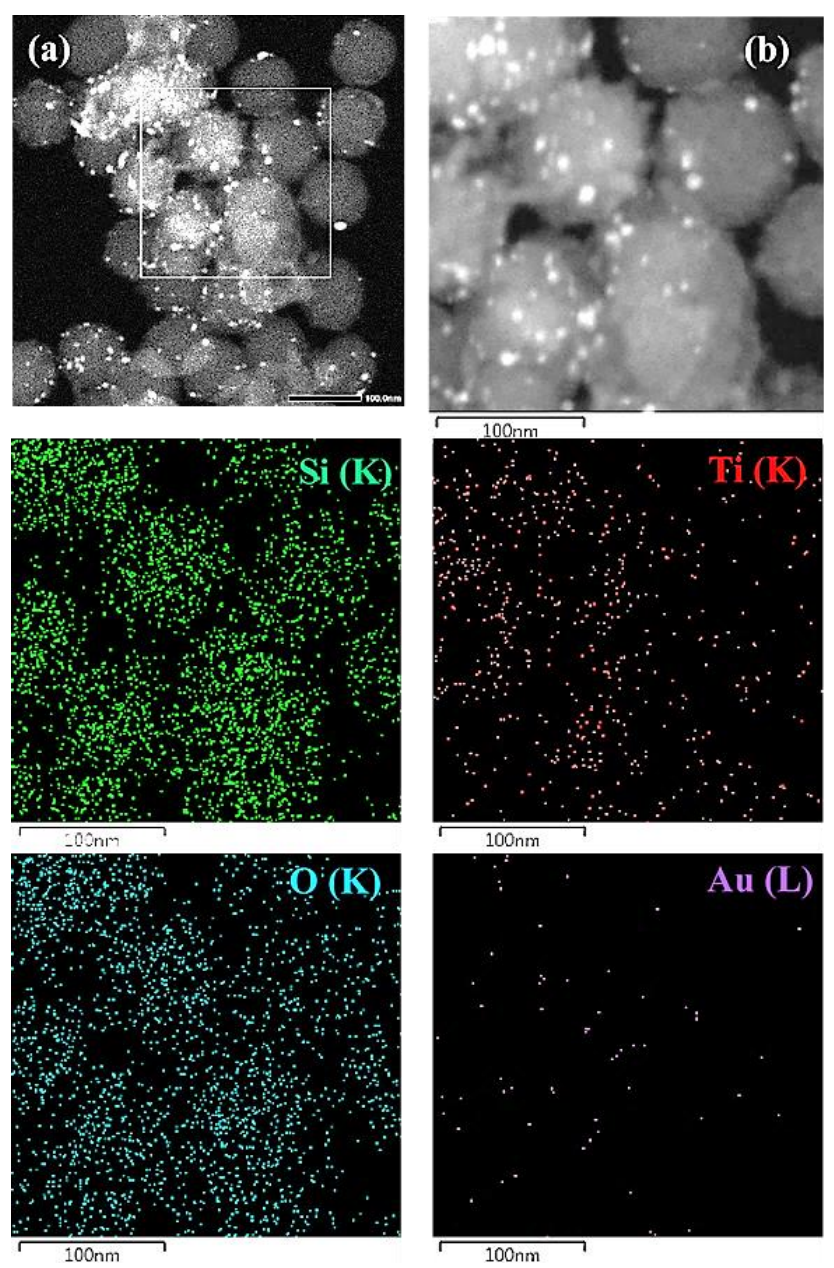

Figure 3 : (a-b) HAADF-STEM images and EDS elemental mapping of $\mathrm{Si}(\mathrm{K})$, $\mathrm{Ti}(\mathrm{K}), \mathrm{O}(\mathrm{K})$ and $\mathrm{Au}(\mathrm{L})$ for the nanocomposite $\mathrm{SiO}_{2} @ \mathrm{Au} @ \mathrm{TiO}_{2}$ with $0.5 \mathrm{wt} \%$ ratio.

interaction that could rationalize the observed red-shift. ${ }^{17}$ This redshift arises due to an overall increase in the refractive index of the dielectric environment surrounding the AuNPs. Comparing both systems, in the case of supported sample $\left(\mathrm{SiO}_{2} @ \mathrm{TiO}_{2} @ \mathrm{Au}\right)$ the AuNPs are surrounded on the one side by $\mathrm{TiO}_{2}$ with high refractive index $\left(\mathrm{n}_{\mathrm{TiO} 2}=2.1^{43}\right)$ and from the other side by air $\left(\mathrm{n}_{\mathrm{air}}=1\right)$. In the $\mathrm{SiO}_{2} @ \mathrm{Au} @ \mathrm{TiO}_{2}$ system, the AuNPs are embedded between $\mathrm{TiO}_{2}$ and $\mathrm{SiO}_{2}\left(\mathrm{n}_{\mathrm{SiO} 2}=1.4^{44}\right)$. For both systems, the LSPR maximum wavelength is the same, even if the surrounding media are not, probably because of the small difference between the air and $\mathrm{SiO}_{2}$ refractive indexes.

It is worth mentioning the change of the LSPR intensity in each system. As the AuNPs loading increases, the LSPR intensity shows an increase for $\mathrm{SiO}_{2} @ \mathrm{TiO}_{2} @ \mathrm{Au}$ system, following the AuNPs ratio (Figure 4.a). The same observation was made when AuNPs are embedded between $\mathrm{SiO}_{2}$ and $\mathrm{TiO}_{2}$, but the enhancement of the LSPR absorption band is much higher. The enhancement is $\sim 1.7$ fold higher for 1\%wt AuNPs ratio before it drastically decreases (Figure 4.b). The decrease of the LSPR intensity is unexpected since usually the collective oscillation of the electrons after excitation usually tends to increase with the gradual increase of the AuNPs loading. However, no physical explanation could be identified for this unexpected result.

The photocatalytic efficiency of plasmonic core-shell materials was investigated for hydrogen production from 1:3 v/v methanol/water solution, under UV-visible light illumination (Mercury lamp 150
W) and shown in Figure 5. $\mathrm{SiO}_{2} @ \mathrm{TiO}_{2}$ core-shell with no gold exhibited very low activity for hydrogen production compared to nanocomposite materials. Published studies ${ }^{4-6,45}$ report on the beneficial effect of AuNPs supported on $\mathrm{TiO}_{2}$ surface on hydrogen production. In agreement with these studies, AuNPs supported $\mathrm{SiO}_{2} @ \mathrm{TiO}_{2}$ system improve the photocatalytic production of hydrogen compared to metal-free sample. Surprisingly, covering AuNPs by $\mathrm{TiO}_{2}$ drastically boost the production of hydrogen, and it is much higher compared to conventional sample (AuNPs growth on the core-shell surface).
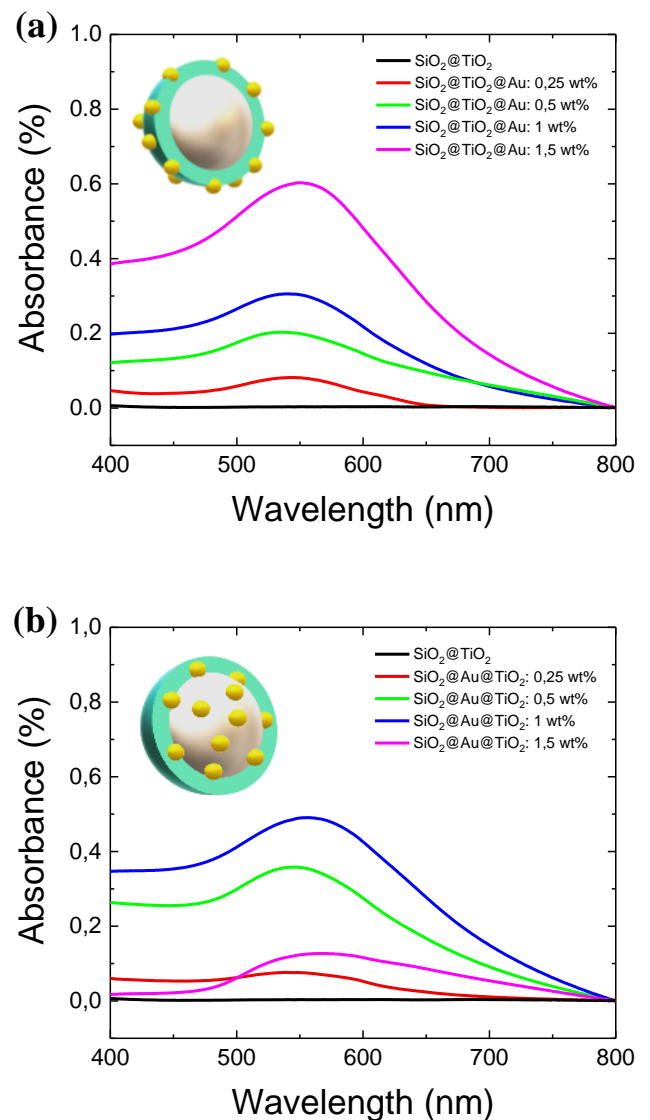

Figure 4: Experimental absorption spectra measured in the range of visible range for core-shell nanocomposites for both systems and at variable AuNPs weight ratio. As a control, $\mathrm{SiO}_{2} @ \mathrm{TiO}_{2}$ core-shell shows no absorption in the 400-800 $\mathrm{nm}$ wavelength range.

The $\mathrm{H}_{2}$ production was 6.7 and 10 times fold higher for 0.5 and 1 wt $\%$ of AuNPs ratio (Figure 5.b), respectively, compared to the best photocatalyst of the $\mathrm{SiO}_{2} @ \mathrm{TiO}_{2} @$ Au series (Figure 5.a). Under UV-visible illumination, the rate of hydrogen generation was significantly improved and reached $12 \mathrm{mmol} . \mathrm{h}^{-1} \cdot \mathrm{g}^{-1}$ for $1 \mathrm{wt} \%$ of $\mathrm{Au}$ ratio. The photocatalytic efficiency was compared to $\mathrm{Pt} / \mathrm{TiO}_{2} \mathrm{P} 25$ in the same reaction conditions. The rate of $\mathrm{H}_{2}$ production was 13.6 mmol. $\mathrm{h}^{-1} \cdot \mathrm{g}^{-1}$ using $1 \mathrm{wt} \%$ of Pt and showed efficiency as good as $\mathrm{SiO}_{2} @ \mathrm{Au} @ \mathrm{TiO}_{2}$ with 1 wt $\%$.

It appears that the photocatalytic performance of the plasmonic $\mathrm{SiO}_{2} @ \mathrm{Au} @ \mathrm{TiO}_{2}$ core-shell photocatalyst rather follows the evolution of the LSPR intensity as opposed to the AuNPs ratio. In the meantime, no such conclusion could be made for $\mathrm{SiO}_{2} @ \mathrm{TiO}_{2} @ \mathrm{Au}$ system. Indeed, for the maximum rate of $\mathrm{H}_{2}$ production ( $\mathrm{SiO}_{2} @ \mathrm{Au} @ \mathrm{TiO}_{2}$ with 1wt \% of AuNPs loading) the LSPR showed 
the highest intensity. As the LSPR decreased, the photocatalytic efficiency of hydrogen production also decreased. This suggests that the LSPR acts as a promoter of the $\mathrm{H}_{2}$ production since the reaction has been performed under UV-visible illumination. Evidences of the role played by AuNPs in enhancing the photocatalytic activity of $\mathrm{TiO}_{2}$ photocatalyst has been reported under both UV-visible and visible illumination for $\mathrm{SiO}_{2} @ \mathrm{Au} @ \mathrm{TiO}_{2 .}{ }^{17}$ Radiative (including near-fields and scattering mechanism) and non-radiative phenomena were suggested to describe the photocatalytic mechanism. ${ }^{46}$
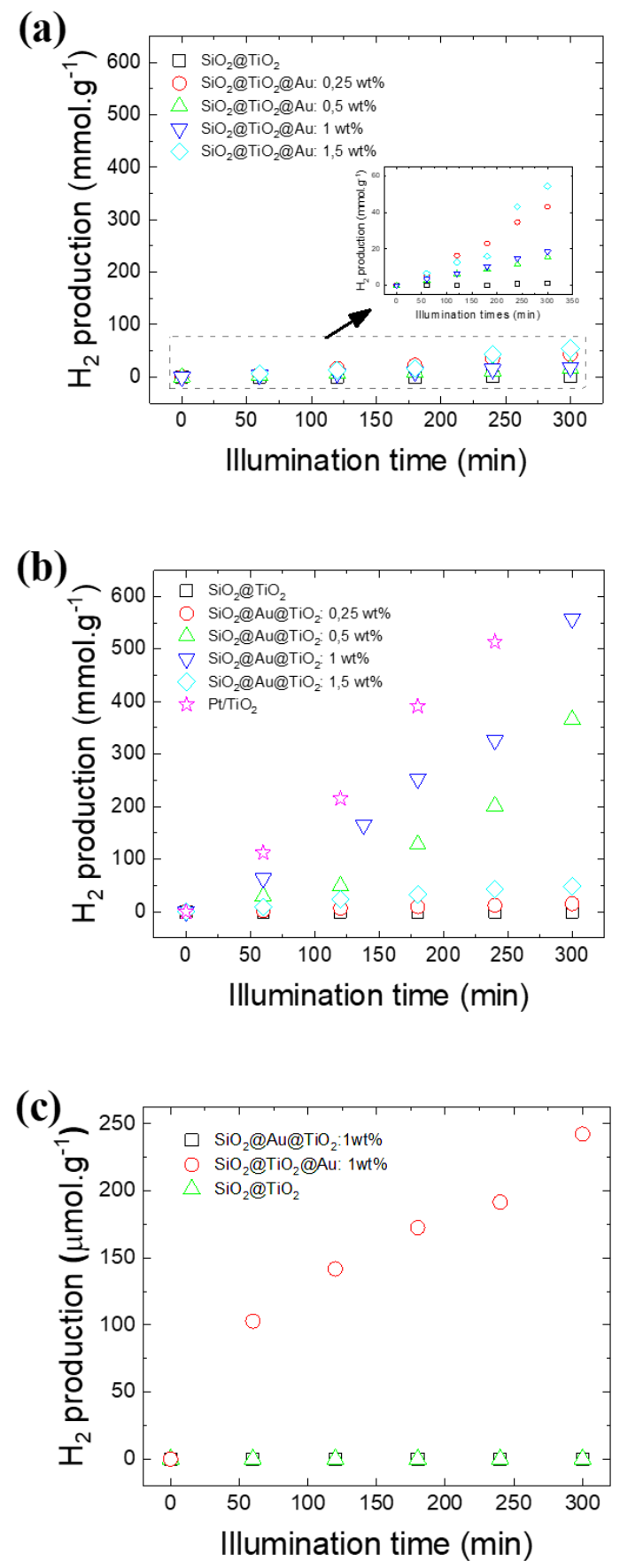

Figure 5: Hydrogen production under UV-visible illumination for different AuNPs loadings $(0.25,0.5,1$, and $1.5 \mathrm{wt} \%)$ for both core-shell systems: (a) $\mathrm{SiO}_{2} @ \mathrm{TiO}_{2} @ \mathrm{Au},(\mathrm{b}) \mathrm{SiO}_{2} @ \mathrm{Au} @ \mathrm{TiO}_{2}$ under UV-visible illumination, and (c) hydrogen production under visible light illumination $(\lambda>420 \mathrm{~nm})$
The first mechanism involves the interaction of the LSPR of AuNPs with incident light resulting in local enhancement of electromagnetic near-fields at the immediate vicinity of the $\mathrm{TiO}_{2}$ surface. The radiative energy transfer mechanism in nanocomposite system reaches its maximum when an overlap of the nanoparticles LSPR band and the semiconductor electronic band gap is obtained. ${ }^{14}$ Therefore, the radiative effect should bear a small impact since the LSPR band (visible) is spectrally misaligned with the $\mathrm{TiO}_{2}$ absorption (UV). Additionally, AuNPs are too small to consider any light scattering of the electric field enhancement. ${ }^{18}$ Considering the core-shell configuration of our photocatalysts, mainly the so-called "non-radiative" effect could mostly explain the enhancement of the photocatalytic performance. In the context of hydrogen production, the kinetics of the hydrogen ion reduction at the surface of $\mathrm{TiO}_{2}$ is very low due to its large band gap and fast recombination charge carriers. Under the UV-visible illumination, AuNPs exhibit an LSPR, i.e. collective oscillations of free-electrons, in response to the incident electromagnetic fields. Indeed, the

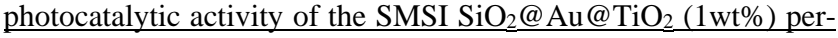
formed under visible illumination exhibited very good photoactivty for the hydrogen production, as shown in Figure 5.c, while no hydrogen was detected either for $\mathrm{SiO}_{2} @ \mathrm{TiO}_{2}$ or $\mathrm{SiO}_{2} @ \mathrm{TiO}_{2} @ \mathrm{Au}$ (1wt $\%)$. The $\mathrm{H}_{2}$ produced after 5 hours of irradiation was 240 $\mu$ mol.g $\mathrm{g}^{-1}$ with a rate of $52 \mu \mathrm{mol} . \mathrm{h}^{-1} \cdot \mathrm{g}^{-1}$. The mechanism behind the $\underline{\mathrm{H}}_{2}$ production remains not clear, especially the holes generation needed for the methanol dissociative adsorption. The later, likely occurs at the interface $\mathrm{Au} / \mathrm{TiO}_{2}$ where holes were reported to be positioned. ${ }^{47}$ The LSPR-excited energetic electrons (hot electrons) either contributed to the reduction of hydrogen ions, or injected to $\mathrm{TiO}_{2}$ raising the $\mathrm{H}_{2}$ formation photocatalytic rate. It has been shown that hot electrons can hardly pass through an insulating barrier with a thickness greater than $10 \mathrm{~nm} .{ }^{14}$ Hence, the $\mathrm{H}_{2}$ production rate increase could be mediated by the hot electron transfer from AuNPs to $\mathrm{TiO}_{2}$ considering the visible light illumination. Although the nanocomposite core-shell system exhibits improved performance compared to $\mathrm{SiO}_{2} @ \mathrm{TiO}_{2}$ photocatalyst, it is obvious that the SMSI of AuNPs in the core-shell nanostructure leads to much higher photocatalytic efficiency for hydrogen production. Thus, the charge transfer on both nanocomposite systems should be considered to define the active site where the photocatalytic reaction occurs. As it has been reported, the charge transfer of gold coupled to $\mathrm{TiO}_{2}$ junction is quite complex. Accordingly, tracking the charge carrier dynamics as well as their lifetime under selective wavelength excitation using TRMC tools will enable further understanding of the difference between the two systems.

The TRMC, as a contactless technique, was used to evaluate the AuNPs effect on the charge carriers density and dynamics for each system at different AuNPs loading. The TRMC signal mainly arises from photogenerated charge carriers produced or transferred at the surface of $\mathrm{TiO}_{2}$ semiconductor. Furthermore, the TRMC signal is mainly related to the electrons since holes are heavier. Thus, their mobility is limited and holes are trapped in the bulk at the early time range $\mathrm{e}^{34,48}$ Therefore, the signal observed from the TRMC is correlated to the electron density at the surface of $\mathrm{TiO}_{2}$ shell after the laser excitation in the early stage, and the decays of free electron number is caused by recombination, trapping and capture by AuNPs. ${ }^{4,27}$ Figure 6 shows the TRMC signal obtained from both systems at different AuNPs loading, after $350 \mathrm{~nm}$ laser pulses excitation (UV illumination). The signal to noise measured on our experiment was about 3 to 1 , which is regarding the thickness of the $\mathrm{TiO}_{2}$ overlayer is reasonable. Core-shell $\mathrm{SiO}_{2} @ \mathrm{TiO}_{2}$ nanospheres were assumed to have the same signal after UV light excitation, and therefore AuNPs would not affect the absorption of photons in the UV range (no structural modification in $\mathrm{TiO}_{2}$ ). Gold-free $\mathrm{SiO}_{2} @ \mathrm{TiO}_{2}$ sample showed a low signal after UV light excitation, which is due to the thin shell layer at the surface $(4-10 \mathrm{~nm})$ as 
shown in Figure 6.a. Given the TRMC results, it seems obvious that the photogenerated charge carriers density relies on the system. Indeed, after UV light excitation the photogenerated charge carriers density undoubtedly increases for $\mathrm{SMSI}_{\mathrm{SiO}} @ \mathrm{Au} @ \mathrm{TiO}_{2}$ system compared to AuNPs-free sample, while in the case of $\mathrm{SiO}_{2} @ \mathrm{TiO}_{2} @$ Au system, the signal TRMC decreases dramatically. At an early excitation stage, $\mathrm{SMSI} \mathrm{Au} / \mathrm{TiO}_{2}$ in the core-shell system collect the photogenerated electrons and inject them back at the $\mathrm{TiO}_{2}$ surface leading to an increase in the TRMC signal. This complex pathway explain how the quenching of the photogenerated charge carriers is not observed for $\mathrm{SMSISiO}_{2} @ \mathrm{Au} @ \mathrm{TiO}_{2}$ system. The transfer of hot electrons from AuNPs is a well-known process compared to the opposite trajectory. Electrons obtained under UV illumination by energy higher than the band gap energy of $\mathrm{TiO}_{2}$ are indeed able to surround the Schottky barrier (SB) and get trapped by AuNPs. The SB in $\mathrm{Au} / \mathrm{TiO}_{2}$ system has been estimated to be $0.23 \mathrm{eV}^{49}$ and the energy of the conduction band of the $\mathrm{TiO}_{2}$ of $0.16 \mathrm{eV} .{ }^{50}$ Accordingly, knowing that the Fermi level for noble metals is around $0 \mathrm{eV}$ on the normal hydrogen electrode scale, ${ }^{8,51}$ the irradiation of $\mathrm{TiO}_{2}$ with energy higher than $3.27 \mathrm{eV}$ (considering anatase phase with a band gap of $3.2 \mathrm{eV}^{52}$ ) or wavelength lower than $379 \mathrm{eV}$ will produce electrons with enough energy to pass through the SB and then be trapped by AuNPs. ${ }^{53}$ This pathway was observed for $\mathrm{Au} / \mathrm{TiO}_{2}$ system. As expected, under mixed UVvisible light irradiation hot electrons injected from the AuNPs to $\mathrm{TiO}_{2}$ under visible light irradiation surmount the $\mathrm{SB}$, and flow back into the $\mathrm{TiO}_{2}$. While in $\mathrm{SiO}_{2} @ \mathrm{TiO}_{2} @ \mathrm{Au}$ system, the signal TRMC decreases dramatically. In $\mathrm{SiO}_{2} @ \mathrm{TiO}_{2} @ \mathrm{Au}$ system, the weak TRMC signal (low charge carrier density) could be due to: 1) shield effect caused by AuNPs, 2) surface recombination centers created by the synthesis method, and 3) fast electron scavenge by the metal (<10 ns). ${ }^{4,11}$ The first two hypotheses could not explain the weak TRMC signal for $\mathrm{SiO}_{2} @ \mathrm{TiO}_{2} @ \mathrm{Au}$ compared to that of $\mathrm{SiO}_{2} @ \mathrm{Au} @ \mathrm{TiO}_{2}$. As we recently showed, AuNPs do not affect the electric field after illumination regardless of where AuNPs are deposited, since their size is small. ${ }^{17}$ Therefore, the electrons are scavenged by AuNPs drastically reducing the charge carrier density at the surface of $\mathrm{TiO}_{2},{ }^{54}$ in agreement with the photocatalytic production of hydrogen results.

The TRMC results enable to shed light on the effect of the localization of AuNPs on the photogenerated charge carriers' dynamics, which is correlated to the photocatalytic efficiency. The electron transfer occurring in both systems follows different physical pathway, leading to drastically variable photocatalytic efficiency. The main consequence of modulating the core-shell system is that the active sites where hydrogen ions reduction reactions occur are different. After trapping the photogenerated electrons from the conduction band of $\mathrm{TiO}_{2}$ in $\mathrm{SiO}_{2} @ \mathrm{TiO}_{2} @ \mathrm{Au}$ system, AuNPs reduce hydrogen ions to form $\mathrm{H}_{2}$ molecules. In this case, AuNPs as the active sites are much less efficient for the reduction reaction compared to the $\mathrm{TiO}_{2}$ active sites in $\mathrm{SiO}_{2} @ \mathrm{Au} @ \mathrm{TiO}_{2}$ system. In the latter, AuNPs act as a promoter of the photogenerated electron lifetime via different mechanism. The electrons are transferred from $\mathrm{TiO}_{2}$ to $\mathrm{Au}$, and then are injected back to $\mathrm{TiO}_{2}$ overpassing the Shottcky barrier, speeding up the kinetics of hydrogen production. The electronic properties of the samples loaded with $1 \mathrm{wt} \%$ of AuNPs were studied under $550 \mathrm{~nm}$ laser excitation, and the results are shown in Figure 6.c. A small TRMC signal was observed for the SMSI SiO $2 @ \mathrm{Au} @ \mathrm{TiO}_{2}$ sample, whereas no signal for classical system (as for $\mathrm{SiO}_{2} @ \mathrm{TiO}_{2}$, results not shown), confirming the efficient electron generation and their transfer in the conduction band of $\mathrm{TiO}_{2}$ overlayer. This result does not exclude the generation of free electrons at the surface of AuNPs in the classical system, but only confirms the beneficial effect of the SMSI concept toward efficient electron transfer from $\mathrm{AuNPs}$ to $\mathrm{TiO}_{2}$ under visible light excitation.

The mechanism of the charge transfer does not address the problem of minority charge-carrier diffusion length encountered in both systems. The diffusion length could be considered as detrimental parameter, particularly when the energetic charge carriers are produced far from the active sites. The difference of the hydrogen production rate in both systems cannot be restricted to the photonic effect and/or to the charge transfer. In fact, the active sites cover larger surface in $\mathrm{SMSI} \mathrm{SiO}_{2} @ \mathrm{Au} @ \mathrm{TiO}_{2}$ system than in $\mathrm{SiO}_{2} @ \mathrm{TiO}_{2} @ \mathrm{Au}$ system (since AuNPs are the active sites in the latter case). Furthermore, considering the electron diffusion length as well as the distance between the adsorbed $\mathrm{MeOH}$ and the reductive species, the kinetic of dissociative adsorption of $\mathrm{MeOH}$ and the reduction of $\mathrm{H}^{+}$over both systems should be addressed further understand the difference of photoefficiency. Schematically, the reaction pathway of the photocatalytic methanol-water $(25 / 75 \mathrm{v} / \mathrm{v}) \mathrm{de}-$ composition reaction for hydrogen production over nanocomposite system is as follows s $^{1,55}<$ sup $>1,55</$ sup $>$ :

$$
\begin{aligned}
& \mathrm{MeOH} \underset{k_{1}}{\stackrel{\text { hv+Cat. }}{\longrightarrow}} \mathrm{HCHO}+\mathrm{H}_{2} \\
& \mathrm{HCOH}+\mathrm{H}_{2} \mathrm{O} \stackrel{\text { hv+Cat. }}{\longrightarrow} \mathrm{HCO}_{2} \mathrm{H}+\mathrm{H}_{2} \\
& \mathrm{HCO}_{2} \mathrm{H} \stackrel{\text { hv+Cat. }}{\underset{k_{3}}{\longrightarrow}} \mathrm{CO}_{2}+\mathrm{H}_{2}
\end{aligned}
$$

With the overall reaction being

$\mathrm{MeOH}+\mathrm{H}_{2} \mathrm{O} \underset{k_{1}}{\stackrel{\text { hv+Cat. }}{\longrightarrow}} \mathrm{CO}_{2}+3 \mathrm{H}_{2}$

The hydrogen production kinetics would then be related to the dissociative adsorption of $\mathrm{MeOH}$, since it would initiate the formation of $\mathrm{H}_{2}$ molecules and the water splitting. The illumination induces a dissociative adsorption of methanol followed by ethoxide formation and hydrogen ion $\left(\mathrm{H}^{+}\right)$release, which would be adsorbed at the $\mathrm{TiO}_{2}$ surface. ${ }^{34}$ The kinetics of adsorption/desorption of methanol should determine the kinetics of the reaction " $k_{1}$ ". DFT calculations were performed to further understand the difference in adsorption energies resulting from the two core-shell systems; This was performed by simulating the adsorption of single methanol molecule on the surface of $\mathrm{SiO}_{2} @ \mathrm{TiO}_{2} @ \mathrm{Au}$ and SMSI $\mathrm{SiO}_{2} @ \mathrm{Au} @ \mathrm{TiO}_{2}$. Four initial adsorption sites were considered for the former material because of the added complexity arising from the presence of the gold cluster, while two initial configurations were considered for the latter (supporting information Figure S1 and S2). Each of these adsorption scenarios were geometricallyoptimized at fixed lattice parameters to find the most stable complex, and adsorption energies were compared to determine the most stable site. For $\mathrm{SiO}_{2} @ \mathrm{TiO}_{2} @ \mathrm{Au}$, methanol adsorbs on the five-coordinated titanium $\left(\mathrm{Ti}_{5 \mathrm{c}}\right)$ on the surface near the gold cluster interface as expected with an adsorption energy of $-1.0788 \mathrm{eV}$ (Figure 7.a), whereas in the SMSISiO $\mathrm{S}_{2} @ \mathrm{Au} @ \mathrm{TiO}_{2}$ model, adsorption also occurs on such a titanium site. However, with the absence of gold, the adsorption energy is weaker at $-0.9479 \mathrm{eV}$ (Figure 7.b).

The adsorption distance in both systems results is different by only $0.012 \AA$, which is not enough to cause the relatively large difference in adsorption energies of $0.13 \mathrm{eV}$. This result demonstrates 
that the rate of methanol adsorption/desorption at the surface of SMSI $\mathrm{SiO}_{2} @ \mathrm{Au} @ \mathrm{TiO}_{2}$ system would occur faster compared to classical $\mathrm{SiO}_{2} @ \mathrm{TiO}_{2} @$ Au. With a stronger adsorption found in $\mathrm{SiO}_{2} @ \mathrm{TiO}_{2} @ \mathrm{Au}$, it is speculated that this nanocomposite photocatalyst exhibits lower activity due to reduced desorption of methanol from the surface, a crucial step in the hydrogen production from methanol aqueous solution; This is in agreement with the photocatalytic data shown in Figure 5. Furthermore, the reduction of hydrogen ions adsorbed at the $\mathrm{TiO}_{2}$ surface by AuNPs to $\mathrm{H}_{2}$ molecules should also be considered. In order to achieve an efficient reaction, the adsorption site of hydrogen atoms should most likely occurs at the $\mathrm{Au} / \mathrm{TiO}_{2}$ interface. ${ }^{56}$ The mechanism of the hydrogen reduction in $\mathrm{SiO}_{2} @ \mathrm{Au} @ \mathrm{TiO}_{2}$ system is favorable since a $\mathrm{TiO}_{2}$ overlayer surrounded the AuNPs. Thus, the adsorbed $\mathrm{H}^{+}$ions are reduced by the electrons available at the $\mathrm{TiO}_{2}$ surface (electrons are injected back from AuNPs to $\mathrm{TiO}_{2}$ ) (Figure 7.d). The mechanism is probably different in the case of $\mathrm{SMSI} \mathrm{SiO}_{2} @ \mathrm{TiO}_{2} @ \mathrm{Au}$ system (Figure 7.c), which has a similar configuration than that reported by Yang et al. ${ }^{56}$. In the latter configuration, the hydrogen reduction reaction is limited by the distance between adsorption site and AuNPs as well as the diffusion kinetic of these atoms from the $\mathrm{TiO}_{2}$ surface to reach AuNPs active sites (Figure 7.c). To reach an efficient reduction of hydrogen ions, they have to migrate from the adsorption site of methanol to the active site (AuNPs). However, if the hydrogen atoms are not reduced (produced far from the active site) they would migrate to the bulk. The diffusion of the hydrogen atoms over the surface is unlikely since the migration in the bulk is thermodynamically spontaneous process. ${ }^{57}$ This configuration suggests the formation of $\mathrm{H}_{2}$ molecules in $\mathrm{TiO}_{2}$ bulk, from which the desorption is kinetically difficult.

\section{Conclusion}

As a summary, a successful method was applied for a design of tunable core-shell plasmonic nanostructure. The multistep synthesis method enables a specific control of the nanostructure and AuNPs were deposited with a narrow size distribution, whatever where the AuNPs were deposited. The LSPR intensity of AuNPs was found very sensitive to the localization of the AuNPs and to the surrounding media. Furthermore, the electronic properties assessed by TRMC showed an enhancement of the photogenerated charge carriers under UV illumination for $\mathrm{SMSI} \mathrm{SiO}_{2} @ \mathrm{Au} @ \mathrm{TiO}_{2}$ system and a scavenger role played by AuNPs in $\mathrm{SiO}_{2} @ \mathrm{TiO}_{2} @ \mathrm{Au}$ system. This result is in agreement with the photocatalytic efficiency. The photocatalytic activity for $\mathrm{H}_{2}$ production was strongly affected by the localization of AuNPs. Strong metal-support interaction between AuNPs and the titania shell showed better activity, with optimal $\mathrm{Au} / \mathrm{TiO}_{2}$ ratio about $1 \%$ wt. Finally, we found that the rate of adsorption/desorption of methanol is a crucial step in the hydrogen production.

\section{ASSOCIATED CONTENT}

Supporting Information

Initial configurations that have been considered for DFT calculations. The Supporting Information is available free of charge on the ACS Publications website.

\section{AUTHOR INFORMATION}

Cong Wang acknowledges the CSC for financial support.
Corresponding Author

* mohamed-nawfal.ghazzal@u-psud.fr,

Tel: +33169155602

Laboratoire de Chimie Physique

UMR8000 - Université Paris-Sud, Université Paris-Saclay

Bâtiment 349 - Campus d'Orsay

15 , avenue Jean Perrin

91405 Orsay, France

Notes

The authors declare no competing financial interests.

\section{ACKNOWLEDGMENT}

\section{REFERENCES}

(1) Tomoji Kawai; Tadayoshi Sakata. Photocatalytic Hydrogen Production. Chem. Commun. 1980, 15, 694 695.

Courbon, H.; Herrmann, J.; Pichat, P. Effect of Platinum Deposits on Oxygen Adsorptiorl and Oxygen Isotope Exchange over Variously Pretreated, UltravioletIlluminated Powder TiO2. J. Phys. Chem. 1984, 88, 5210 5214.

(3) Murdoch, M.; Waterhouse, G. I. N.; Nadeem, M. A.; Metson, J. B.; Keane, M. A.; Howe, R. F.; Llorca, J.; Idriss, H. The Effect of Gold Loading and Particle Size on Photocatalytic Hydrogen Production from Ethanol over $\mathrm{Au} / \mathrm{TiO} 2$ Nanoparticles. Nat. Chem. 2011, 3, 489-.

Méndez-Medrano, M. G.; Kowalska, E.; Lehoux, A.; Herissan, A.; Ohtani, B.; Rau, S.; Colbeau-Justin, C.; Rodríguez-López, J. L.; Remita, H. Surface Modification of $\mathrm{TiO}_{2}$ with $\mathrm{Au}$ Nanoclusters for Efficient Water Treatment and Hydrogen Generation under Visible Light. J. Phys. Chem. C 2016, 120 (43), 25010-25022.

(5) Jianming Zhang, Xin Jin, Pablo I. Morales-Guzman, Xin $\mathrm{Yu}$, Hong Liu, Hua Zhang, Luca Razzari, and J. P. C. Engineering the Absorption and Field $\mathrm{Au}-\mathrm{TiO} 2$ Whispering Gallery Mode. ACS nano. 2016, pp 44964503.

(6) Seh, Z. W.; Liu, S.; Low, M.; Zhang, S. Y.; Liu, Z.; Mlayah, A.; Han, M. Y. Janus Au-TiO 2 Photocatalysts with Strong Localization of Plasmonic near-Fields for Efficient Visible-Light Hydrogen Generation. Adv. Mater. 2012, 24 (17), 2310-2314.

Awazu, K.; Fujimaki, M.; Rockstuhl, C.; Tominaga, J.; Murakami, H.; Ohki, Y.; Yoshida, N.; Watanabe, T. A Plasmonic Photocatalyst Consisting of Sliver Nanoparticles Embedded in Titanium Dioxide. J. Am. Chem. Soc. 2008, 130 (5), 1676-1680.

Suljo Linic, P. C. and D. B. I. Plasmonic-Metal Nanostructures for Efficient Conversion of Solar to Chemical Energy. Nat. Mater. 2011, 10, 911-921.

(9) Verbruggen, S. W.; Keulemans, M.; Filippousi, M.; Flahaut, D.; Van Tendeloo, G.; Lacombe, S.; Martens, J. A.; Lenaerts, S. Plasmonic Gold-Silver Alloy on TiO2photocatalysts with Tunable Visible Light Activity. Appl. Catal. B Environ. 2014, 156-157, 116-121.

(10) Kowalska, E.; Abe, R.; Ohtani, B. Visible Light-Induced 
Photocatalytic Reaction of Gold-Modified Titanium(Iv) Oxide Particles: Action Spectrum Analysis. Chem. Commun. 2009, No. 2, 241-243.

(11) Luna, A. L.; Novoseltceva, E.; Louarn, E.; Beaunier, P.; Kowalska, E.; Ohtani, B.; Valenzuela, M. A.; Remita, H.; Colbeau-Justin, C. Synergetic Effect of $\mathrm{Ni}$ and $\mathrm{Au}$ Nanoparticles Synthesized on Titania Particles for Efficient Photocatalytic Hydrogen Production. Appl. Catal. B Environ. 2016, 191, 18-28.

(12) Ye, M.; Zhou, H.; Zhang, T.; Zhang, Y.; Shao, Y. Preparation of SiO2@Au@TiO2core-Shell Nanostructures and Their Photocatalytic Activities under Visible Light Irradiation. Chem. Eng. J. 2013, 226, 209 216.

(13) Sousa-Castillo, A.; Comesaña-Hermo, M.; RodríguezGonzález, B.; Pérez-Lorenzo, M.; Wang, Z.; Kong, X. T.; Govorov, A. O.; Correa-Duarte, M. A. Boosting Hot Electron-Driven Photocatalysis through Anisotropic Plasmonic Nanoparticles with Hot Spots in AuTiO2Nanoarchitectures. J. Phys. Chem. C 2016, 120 (21), 11690-11699.

(14) Cushing, S. K.; Li, J.; Bright, J.; Yost, B. T.; Zheng, P.; Bristow, A. D.; Wu, N. Controlling Plasmon-Induced Resonance Energy Transfer and Hot Electron Injection Processes in Metal@TiO 2 Core-Shell Nanoparticles. J. Phys. Chem. C 2015, 119 (28), 16239-16244.

(15) Wu, B.; Liu, D.; Mubeen, S.; Chuong, T. T.; Moskovits, M.; Stucky, G. D. Anisotropic Growth of TiO2onto Gold Nanorods for Plasmon-Enhanced Hydrogen Production from Water Reduction. J. Am. Chem. Soc. 2016, 138 (4), 1114-1117.

(16) Lee, R.; Kumaresan, Y.; Yoon, S. Y.; Um, S. H.; Kwon, I. K.; Jung, G. Y. Design of Gold Nanoparticles-Decorated $\mathrm{SiO} 2$ @TiO 2 Core/Shell Nanostructures for Visible Light-Activated Photocatalysis. RSC Adv. 2017, 7 (13), 7469-7475.

(17) Getaneh Diress Gesesse, Thomas Le Neel, Zhenpeng Cui, Guillaume Bachelier, Hynd remita, Christophe ColbeauJustin, M. N. G. Plasmonic Core-Shell Nanostructure as an Optical Photoactive Nanolens for Enhanced Light Harvesting and Hydrogen Production. Nanoscale 2018, 10, 20140-20146.

(18) Ding, D.; Liu, K.; He, S.; Gao, C.; Yin, Y. LigandExchange Assisted Formation of Au/TiO 2 Schottky Contact for Visible-Light Photocatalysis. Nano Lett. 2014, 14 (11), 6731-6736.

(19) Jia, C.; Li, X.; Xin, N.; Gong, Y.; Guan, J.; Meng, L.; Meng, S.; Guo, X. Interface-Engineered Plasmonics in Metal/Semiconductor Heterostructures. Adv. Energy Mater. 2016, 6 (17), 1-11.

(20) Tauster, S. J.; Fung, S. C.; Garten, R. L. Strong MetalSupport Interactions. Group 8 Noble Metals Supported on TiO2. J. Am. Chem. Soc. 1978, 100 (1), 170-175.

(21) Uchijima, T. SMSI Effect in Some Reducible Oxides Including Niobia. Catal. Today 1996, 28 (1-2), 105-117.

(22) De Leitenburg, C.; Trovarelli, A. Metal-Support Interactions in $\mathrm{Rh} / \mathrm{CeO} 2, \mathrm{Rh} / \mathrm{TiO} 2$, and $\mathrm{Rh} / \mathrm{Nb} 2 \mathrm{O} 5$ Catalysts as Inferred from $\mathrm{CO} 2$ Methanation Activity.

Journal of Catalysis. 1995, pp 171-174.

Fujiwara, K.; Okuyama, K.; Pratsinis, S. E. Metal-Support Interactions in Catalysts for Environmental Remediation. Environ. Sci. Nano 2017, 4 (11), 2076-2092.

Matsubu, J. C.; Zhang, S.; DeRita, L.; Marinkovic, N. S.; Chen, J. G.; Graham, G. W.; Pan, X.; Christopher, P. Adsorbate-Mediated Strong Metal-Support Interactions in Oxide-Supported Rh Catalysts. Nat. Chem. 2017, 9 (2), 120-127.

Strayer, M. E.; Binz, J. M.; Tanase, M.; Kamali Shahri, S. M.; Sharma, R.; Rioux, R. M.; Mallouk, T. E. Interfacial Bonding Stabilizes Rhodium and Rhodium Oxide Nanoparticles on Layered $\mathrm{Nb}$ Oxide and $\mathrm{Ta}$ Oxide Supports. J. Am. Chem. Soc. 2014, 136 (15), 5687-5696.

Xu, M.; Yao, S.; Rao, D.; Niu, Y.; Liu, N.; Peng, M.; Zhai, P.; Man, Y.; Zheng, L.; Wang, B.; et al. Insights into Interfacial Synergistic Catalysis over Ni@TiO 2- x Catalyst toward Water-Gas Shift Reaction. J. Am. Chem. Soc. 2018, 140 (36), 11241-11251.

Li, S.; Xu, Y.; Chen, Y.; Li, W.; Lin, L.; Li, M.; Deng, Y.; Wang, X.; Ge, B.; Yang, C.; et al. Tuning the Selectivity of Catalytic Carbon Dioxide Hydrogenation over Iridium/Cerium Oxide Catalysts with a Strong MetalSupport Interaction. Angew. Chemie - Int. Ed. 2017, 56 (36), 10761-10765.

Shastri, A. G.; Datye, A. K.; Schwank, J. Gold-Titania Interactions: Temperature Dependence of Surface Area and Crystallinity of TiO2 and Gold Dispersion. J. Catal. 1984, 87 (1), 265-275.

Haruta, M.; Su, D.; Isaacs, M. A.; Huang, J.; Tang, H.; Wang, J.; Li, L.; Zhang, B.; Qiao, B.; Liu, X.; et al. Classical Strong Metal-Support Interactions between Gold Nanoparticles and Titanium Dioxide. Sci. Adv. 2017, 3 (10), e1700231.

Dyrbeck, H.; Hammer, N.; Rønning, M.; Blekkan, E. A. Catalytic Oxidation of Hydrogen over $\mathrm{Au} / \mathrm{TiO} 2$ Catalysts. Top. Catal. 2007, 45 (1-4), 21-24.

Panayotov, D. A.; Burrows, S. P.; Yates, J. T.; Morris, J. R. Mechanistic Studies of Hydrogen Dissociation and Spillover on Au/TiO 2: IR Spectroscopy of Coadsorbed $\mathrm{CO}$ and H-Donated Electrons. J. Phys. Chem. C 2011, 115 (45), 22400-22408.

Sun, K.; Kohyama, M.; Tanaka, S.; Takeda, S. A Study on the Mechanism for $\mathrm{H} 2$ Dissociation on Au/TiO 2 Catalysts. J. Phys. Chem. C 2014, 118 (3), 1611-1617.

Jian Zhang, Hai Wang, Liang Wang, Sajjad Ali, Chengtao Wang,Lingxiang Wang, Xiangju Meng, Bo Li, Dang Sheng $\mathrm{Su}$, and F.-S. X. Wet-Chemistry Strong Metal-Support Interactions in Titania-. J. Am. Chem. Soc. 2019, p 2975-2983.

Colbeau-Justin, C.; Kunst, M.; Huguenin, D. Structural Influence on Charge-Carrier Lifetimes in $\mathrm{TiO} 2$ Powders Studied by Microwave Absorption. J. Mater. Sci. 2003, 38 (11), 2429-2437.

Clark, S. J.; Segall, M. D.; Pickard, C. J.; Hasnip, P. J.; Probert, M. I. J.; Refson, K.; Payne, M. C. First Principles Methods Using CASTEP. Zeitschrift für Krist. 2005, 220 (5/6/2005), 567-570. 
Perdew, J. P., Burke, K. \& Ernzerhof, M. Generalized Gradient Approximation Made Simple. Phys. Rev. Lett. 1996, 77 (3), 3865-3868.

(37) Yeh, H. L.; Tai, S. H.; Hsieh, C. M.; Chang, B. K. FirstPrinciples Study of Lithium Intercalation and Diffusion in Oxygen-Defective Titanium Dioxide. J. Phys. Chem. C 2018, 122 (34), 19447-19454.

(38) Burdett, J. K.; Hughbanks, T.; Miller, G. J.; Smith, J. V.; Richardson, J. W. Structural-Electronic Relationships in Inorganic Solids: Powder Neutron Diffraction Studies of the Rutile and Anatase Polymorphs of Titanium Dioxide at 15 and 295 K. J. Am. Chem. Soc. 1987, 109 (12), 36393646.

(39) Gong, X. Q.; Selloni, A.; Dulub, O.; Jacobson, P.; Diebold, U. Small Au and Pt Clusters at the Anatase TiO2(101) Surface: Behavior at Terraces, Steps, and Surface Oxygen Vacancies. J. Am. Chem. Soc. 2008, 130 (1), 370-381.

(40) Grimme, S.; Antony, J.; Ehrlich, S.; Krieg, H. A Consistent and Accurate $\mathrm{Ab}$ Initio Parametrization of Density Functional Dispersion Correction (DFT-D) for the 94 Elements H-Pu. J. Chem. Phys. 2010, 132 (15), 154104.

(41) Kimling, J.; Maier, M.; Okenve, B.; Kotaidis, V.; Ballot, H.; Plech, A. Turkevich Method for Gold Nanoparticle Synthesis Revisited.Pdf. J. Phys. Chem. B 2006, 110 (95 $\mathrm{mL}), 15700-15707$.

(42) Ziegler, C.; Eychmüller, A. Seeded Growth Synthesis of Uniform Gold Nanoparticles with Diameters of 15 - 300 Nm. J. Phys. Chem. C 2011, 115 (11), 4502-4506.

(43) Ghazzal, M. N.; Kebaili, H.; Joseph, M.; Debecker, D. P.; Eloy, P.; De Coninck, J.; Gaigneaux, E. M. Photocatalytic Degradation of Rhodamine 6G on Mesoporous Titania Films: Combined Effect of Texture and Dye Aggregation Forms. Appl. Catal. B Environ. 2012, 115-116, 276-284.

(44) Ghazzal, M. N.; Debecker, D. P.; Gaigneaux, E. M. Ordered and Disordered Evolution of the Pore Mesostructure in Hybrid Silica Anti-Reflective Films Obtained by One-Pot Self-Assembly Method. Thin Solid Films 2016, 611.

(45) Hai, Z.; El Kolli, N.; Uribe, D. B.; Beaunier, P.; JoséYacaman, M.; Vigneron, J.; Etcheberry, A.; Sorgues, S.; Colbeau-Justin, C.; Chen, J.; et al. Modification of TiO2 by Bimetallic $\mathrm{Au}-\mathrm{Cu}$ Nanoparticles for Wastewater Treatment. J. Mater. Chem. A 2013, 1 (36), 10829.

(46) Erwin, W. R.; Zarick, H. F.; Talbert, E. M.; Bardhan, R. Light Trapping in Mesoporous Solar Cells with Plasmonic Nanostructures. Energy Environ. Sci. 2016, 9 (5), 15771601.

(47) Wang, S.; Gao, Y.; Miao, S.; Liu, T.; Mu, L.; Li, R.; Fan, F.; Li, C. Positioning the Water Oxidation Reaction Sites in Plasmonic Photocatalysts. J. Am. Chem. Soc. 2017, 139
(34), 11771-11778.

(48) Tamaki, Y.; Furube, A.; Murai, M.; Hara, K.; Katoh, R.; Tachiya, M. Dynamics of Efficient Electron-Hole Separation in $\mathrm{TiO} 2$ Nanoparticles Revealed by Femtosecond Transient Absorption Spectroscopy under the Weak-Excitation Condition. Phys. Chem. Chem. Phys. 2007, 9 (12), 1453-1460.

(49) Arshad, M. S.; Trafela, Š.; Rožman, K. Ž.; Kovač, J.; Djinović, P.; Pintar, A. Determination of Schottky Barrier Height and Enhanced Photoelectron Generation in Novel Plasmonic Immobilized Multisegmented (Au/TiO2) Nanorod Arrays (NRAs) Suitable for Solar Energy Conversion Applications. J. Mater. Chem. C 2017, 5 (40), 10509-10516.

(50) Zhang, X.; Zhang, L.; Xie, T.; Wang, D. LowTemperature Synthesis and High Visible-Light-Induced Photocatalytic Activity of BiOI / TiO 2 Heterostructures. 2009, 7371-7378.

(51) Naya, S. I.; Teranishi, M.; Aoki, R.; Tada, H. Fermi Level Control of Gold Nanoparticle by the Support: Activation of the Catalysis for Selective Aerobic Oxidation of Alcohols. J. Phys. Chem. C 2016, 120 (23), 12440-12445.

(52) Ghazzal, M. N.; Chaoui, N.; Genet, M.; Gaigneaux, E. M.; Robert, D. Effect of Compressive Stress Inducing a Band Gap Narrowing on the Photoinduced Activities of Sol-Gel TiO2 Films. Thin Solid Films 2011, 520 (3).

(53) Lin, Z.; Wang, X.; Liu, J.; Tian, Z.; Dai, L.; He, B.; Han, C.; Wu, Y.; Zeng, Z.; Hu, Z. On the Role of Localized Surface Plasmon Resonance in UV-Vis Light Irradiated $\mathrm{Au} / \mathrm{TiO} 2$ photocatalysis Systems: Pros and Cons. Nanoscale 2015, 7 (9), 4114-4123.

(54) Subramanian, V.; Wolf, E. E.; Kamat, P. V. Catalysis with TiO2/Gold Nanocomposites. Effect of Metal Particle Size on the Fermi Level Equilibration. J. Am. Chem. Soc. 2004, 126 (15), 4943-4950.

(55) Fretwell, R.; Douglas, P. Nanocrystalline-TiO2-Pt PhotoElectrochemical Cells --- UV Induced Hydrogen Evolution from Aqueous Solutions of Alcohols. Photochem. Photobiol. Sci. 2002, 1 (10), 793-798.

(56) Yang, Y. Z.; Chang, C. H.; Idriss, H. Photo-Catalytic Production of Hydrogen Form Ethanol over $\mathrm{M} / \mathrm{TiO}$ catalysts $(\mathrm{M}=\mathrm{Pd}$, Pt or Rh). Appl. Catal. B Environ. 2006, 67 (3-4), 217-222.

(57) Islam, M. M.; Calatayud, M.; Pacchioni, G. Hydrogen Adsorption and Diffusion on the Anatase TiO2(101) Surface: A First-Principles Investigation. J. Phys. Chem. C 2011, 115 (14), 6809-6814. 